\title{
A Review of Heat Pipe Systems for Heat Recovery and Renewable Energy Application
}

\author{
Vikas Shelke $^{+*}$, R.J.Yadav ${ }^{\dagger}$ and S.B.Girase ${ }^{\dagger}$ \\ †Department of Mechanical Engineering, MIT College of Engineering, Pune-411038, India
}

Accepted 02 March 2016, Available online 15 March 2016, Special Issue-4 (March 2016)

\begin{abstract}
Advancements into the computational studies have increased the development of heat pipe arrangements, displaying multiphase flow regimes and highlighting the broad scope of the respective technology for utilization in passive and active applications. The purpose of this review is to evaluate current heat pipe systems for heat recovery and renewable applications utility. Basic features and limitations are outlined and theoretical comparisons are drawn with respect to the operating temperature profiles for the reviewed industrial systems. Working fluids are compared on the basis of the figure of merit for the range of temperatures. The review established that standard tubular heat pipe systems present the largest operating temperature range in comparison to other systems and therefore offer viable potential for optimization and integration into renewable energy systems
\end{abstract}

Keywords: Heat Pipe Systems, Heat Recovery etc.

\section{Introduction}

A heat pipe is a simple device of very high thermal conductivity with no moving parts that can transport large quantities of heat efficiently over large distances fundamentally at an invariable temperature without requiring any external electricity input. A heat pipe is essentially a conserved slender tube containing a wick structure lined on the inner surface and a small amount of fluid such as water at the saturated state. It is composed of three sections: the evaporator section at one end, where heat is absorbed and the fluid is vaporized; a condenser section at the other end, where the vapor is condensed and heat is rejected; and the adiabaticsection in between, where the vapor and the liquid phases ofthe fluid flow in opposite directions through the core and the wick,
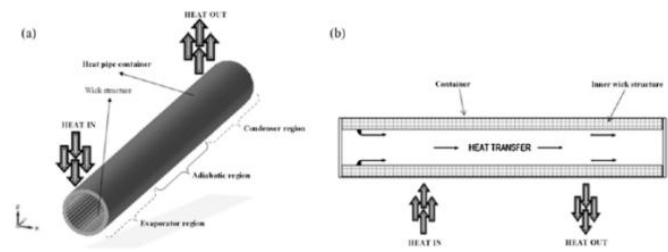

Fig.1 Basic working principle associated with a heat pipe (a) isometric view and (b) sectional view

Respectively, to complete the cycle with no significant heat transfer between the fluid and the surrounding

*Corresponding author: Vikas Shelke medium. the operating pressure and the type of fluid inside the heat pipe depend largely on the operating temperature of the heat pipe. For example, if a heat pipe with water as a working fluid is designed to remove heat at $343 \mathrm{~K}$, the pressure inside the heat pipe must be maintained at $31.2 \mathrm{kPa}$, which is the boiling pressure of water at this temperature. Though water is a suitable fluid to utilize in the moderate temperature range encountered in electronic equipment, various other fluids are used in the manufacturing of heat pipes to allow them to be used in cryogenic as well as hightemperature applications. Another characteristic while selecting the working fluid is the property of surface tension, which must be high in order to increase the capillary effect and being compatible with the wick substance, as well as being chemically stable, readily available, non toxic and inexpensive. Fig. 1 displays the basic working sections of a heat pipe.

Heat pipes are utilized in a wide variety of applications which encounter temperature variations in a heat transfer process. The effectual thermal conductivity of a heat pipe facilitates heat to be transported at high efficiency over large distances. Consequently, heat pipes have been expansively used in various energy storage systems due to their suitability in the role of heat delivery and passive operation. The unique method of operation of heat pipes including phase change materials (PCMs) provide a better efficiency pattern over conventional heat exchangers in major operations including temperature stratification in hot water storage tanks. Another general utility of heat pipes include solar collectors 
where it allows static or flowing water to be heated by the method of transferring the solar thermal energy directly from the sun

\section{The role of heat pipes in heat recovery and energy Conservation}

The demand for utilizing heat pipes in renewable energy systems along with building heat recovery, highlighting novel concepts and requirements is increasing. Several terrestrial applications ranging from solar concentrators to heat exchangers make use of heat pipes for higher and more efficient heat transfer rates. Heat pipes offer distinct advantages over other thermal transfer apparatus due to its passive and compact method of operation along with the various commercial sizes available ranging from micro to a more extensive array making the device suitable for most applications requiring a temperature differential. El-Baky and Mohamed investigated the overall effectiveness of utilizing heat pipe heat exchangers for heat recovery through external airconditioning systems in buildings in order to reduce the cooling load. The thermal performance of the system was analyzed for varying fresh air inlet mass flow rates and temperature stream. A mathematical model was developed based on the experimental setup which included the two air ducts of $0.3 \mathrm{~m} \times 0.22 \mathrm{~m}$ sectional areas along with the heat pipe arrangement comprising of 25 copper tubes with the evaporator and condenser section of $0.2 \mathrm{~m}$ and the adiabatic section of $0.1 \mathrm{~m}$ respectively. $\mathrm{R}-11$ was used as a working fluid at a saturation temperature of $303 \mathrm{~K}$. The findings of the study indicated that effectiveness and heat transfer rates are increased with the increase in fresh air inlet temperature. The study also revealed that the mass flow rate ratio has a significant effect of temperature change of fresh air and heat recovery rate is increased by approximately85\% with the increase in fresh air inlet temperature. Fig. 2describes the schematic of the heat exchanger. Noie-Baghban and Majideian carried out work on the design and build of a heat pipe arrangement to be installed in a heat pipe heat exchanger for the purpose of heat recovery in hospital and laboratory buildings where high air change is a primary requirement. The experimental apparatus include a test-rig comprising of two fans to deliver a flow rate of $0.103 \mathrm{~m} 3 / \mathrm{s}$ through evaporator and condenser. Eight copper pipes with an outside diameter of $15 \mathrm{~mm}$, inside diameter of $9 \mathrm{~mm}$ and length of $600 \mathrm{~mm}$ were utilized along with three types of wicks including the 50 mesh nickel, 250 mesh nickel and 100 mesh stainless steel. The figure of merit of the type of working fluid was established. K-type thermocouples were used for temperature measurements. A mathematical model was established to validate the experimental findings. The work concluded a good correlation between the mathematical and experimental results with respect to the heat transfer rate in the evaporator section of 100 W. Further, the study highlighted the importance of utilizing finned heat pipes and increasing the number of rows along with insulation capability in having a major impact in increasing the overall effectiveness of the system. Various renewable applications are highlighted in this review in order to understand the role of heat pipes to a broader extent. A gas-gas heat pipe heat exchanger consists of a collection of similar heat pipes aligned in a tubular arrangement either vertically, horizontally or aligned at an angle. The evaporation and condensation working principal of the device influences the heat transfer from the countercurrent gas stream which recovers the heat and transports it to the pre-heated air stream. Heat pipe heat exchangers are very useful in industrial heat recovery applications due to its static operation and limited auxiliary power requirements along with its entirely reversible process. Yau and Ahmad zadehtalatapeh reviewed the utility of horizontal pipe heat exchangers as an energy recovery unit in air conditioning systems in tropical climates. The review included literature from previously published work on the vertical and orizontal orientations of heat pipes respectively.

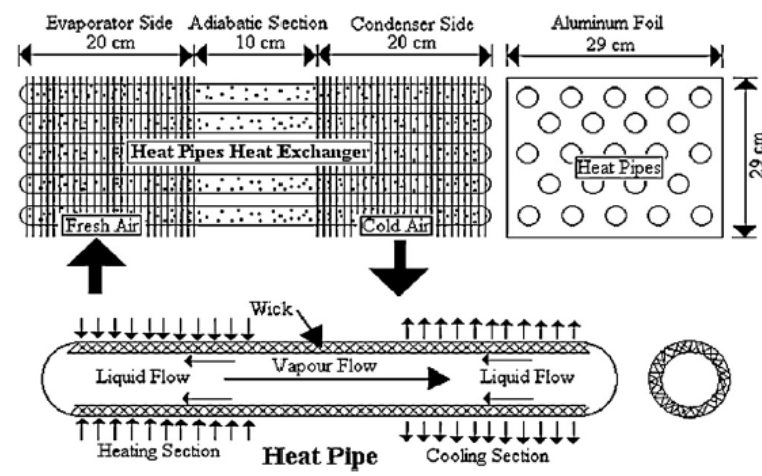

Fig.2 Heat pipe heat exchanger design

$\mathrm{h}$ The work concluded that the application of horizontal heat pipe heat exchangers for both orientations in terms of dehumidification purposes and energy saving is recommended for tropical climates as a highly efficient heat recovery unit. The work further highlighted the transient simulation of installing double heat pipe heat exchanger units in heating, ventilation and air-conditioning systems for reducing energy consumption rates in tropical climatic behavior as displayed in Fig. 3.

One of the most widespread commercial uses of heat pipes is associated with solar collectors in order to transfer the direct and diffuse solar radiation to the water stream. Hussein et al. carried out test work on the comparison of three cross-sectional geometries of wickless heat pipes with varying fill ratios in orderto understand the impact of its performance on flat plate solar collectors in Cairo, Egypt. The manufacturing group comprised of heat pipe cross-sections which included circular, elliptical and semi circular arrangement. Experiments were conducted on the group by incorporating the heat pipes into the solar 
collector array and the comparison results indicated that the elliptical design gave a better performance at $10 \%$ water fill ratios with the circular cross-section design proving optimum at $20 \%$ water fill ratio respectively. Rittidech and Wannapakne carried out extensive work on determining the overall performance capability of a system comprising of a Closed-End Oscillating Heat Pipe (CEOHP) in corporated in to a flat plate solar collector. The thermocouple based experimental test apparatus was inclined at 18 degrees and comprised of a $2 \mathrm{~m}$ zinc sheet coupled with $70 \mathrm{~m}$ of CEOHP copper tubes. The working fluid comprised of R134a at an initial fill ratio of $50 \%$. Fig. 4describes the hematic of the test-rig where A1-A6 is the thermojunction on the collecting plate and G1-G2 is the thermo-junction position on the glass plate respectively. A numerical model wasbuilt to calculate the performance of the system with respect to the plate temperature and ambient temperature and an overall thermal efficiency of $62 \%$ was obtained. The study highlighted the advantages of using CEOHP system in comparison to conventional heat pipe systems on solar collectors in terms of minimal corrosion rate and elimination of freezing during winter.

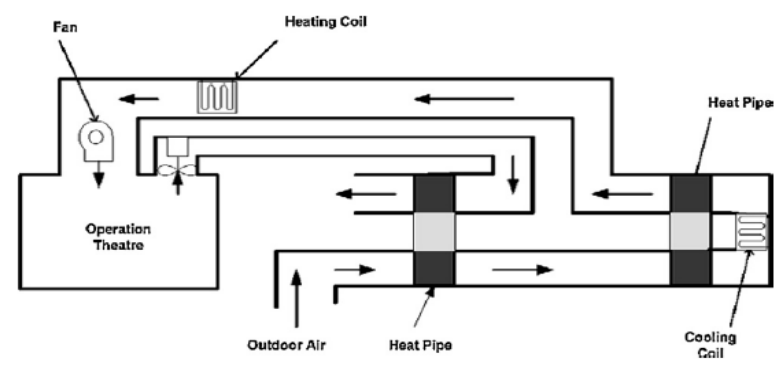

Fig. 3.Schematic of double heat pipe systems in the heating, ventilation and air-conditioning

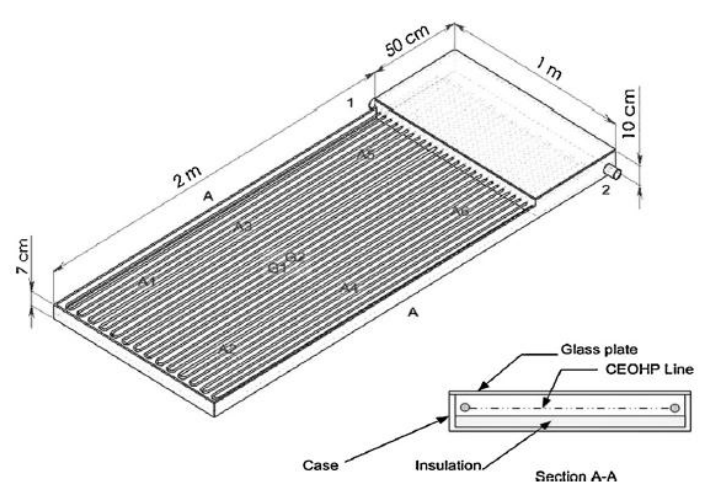

Fig.4 Outline of the thermo-junction positions on collecting and glass plates in the test rig

\section{Conventional heat pipe systems}

Various types of heat pipes are commercially available, in terms of the method of liquid transport from the condenser to the evaporator and functionality. This review provides a source of information based on the current published literature on the different types of existing heat pipes which are utilized for a variety of applications requiring moderate to high temperature fluctuations.

\subsection{Tubular heat pipes}

Conventional tubular heat pipes as displayed in Fig. 5 are the most uncomplicated and accepted type of passive heat transfer devices commercially for use in many terrestrial applications for heat transport over variable distances. The standard operational principle is based on capillary action and the performance is measured in equivalent thermal conductivity. These types can also be used as heat spreaders to isothermalize apparatus where homogeneous temperature patterns are preferred. Liao et al. analyzed the thermal performance of a smooth carbon steel-water heat pipe in comparison to its internally finned equivalent. Various influencing parameters including the inclination angle, working temperatures and heat flux formed the basis of the investigation. The experimental set-up comprised of a fiber glass coated carbon steel pipe with a flat band heater for providing heat flux to the evaporator section.

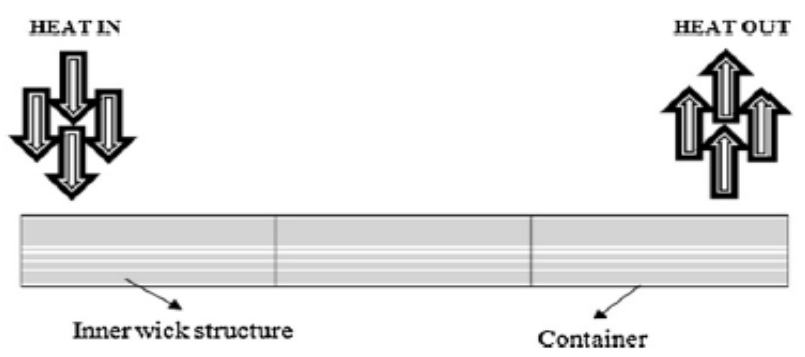

Fig.5 Schematic of a tubular heat pipe

The apparatus was placed on an adjustable workbench for alteration of inclination angles and thermocouples were linked to the data logging system for output results. The work revealed that under experimental conditions, the heat transfer coefficient of the internally finned heat pipe was increased by $50-100 \%$ in comparison to the smooth heat pipe respectively.

Joudi and Witwit carried out work to improve the thermal performance of gravity assisted conventional wickless heat pipes. Experimental study was carried out on the modified copper heat pipe with the introduction of an adiabatic separator. The heat pipe under test was fixed in a rig and coupled with several measuring devices including a digital ammeter and voltmeter inorder to calculate the input power. The heat pipe was insulated with glass wool to minimize heat losses to the environment. The condenser flow rate was kept constant and the temperature was monitored at $23 \pm 2 \circ \mathrm{C}$ and the power input was increased steadily to obtain gradual thermocouple readings. The outcome from the study highlighted 
useful results with respect to the addition of an adiabatic separator in the heat pipe. The study revealed an approximate increase of $35 \%$ in heat transfer coefficient in comparison to conventional heat pipes. The investigation concluded that the addition of an adiabatic separator eradicated the effect of inclination angles above $45^{\circ}$ and decreased the heat pipe working temperature respectively.

\subsection{Variable conductance heat pipes}

Variable Conductance Heat Pipes (VCHPs) are widely utilized in many applications including conventional electronics temperature control. A variable conductance heat pipe or gas-loaded heat pipehas the capability to maintain a device mounted at the evaporator at a near constant temperature, independent of the amount of power being generated by the device. The most familiar VCHPsystems include passive or active feedback-controlled system, both having the capability to control the source of heat at the evaporator end. However, a greater temperature control is obtained using the active system than the comparable passive system. Fig. 6 displays the schematic of a cold-reservoir variable conductance heat pipe

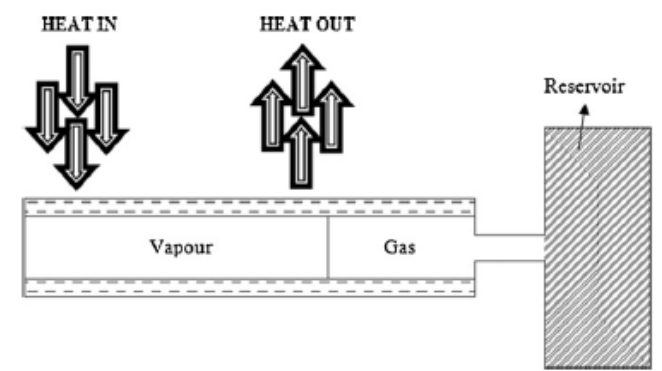

Fig.6Schematic of cold-reservoir variable conductance heat pipe

Sauciuc et analyzed the operation of a VCHP for controlling the temperature of a closed system arrangement of solar collectors. The experimental apparatus included a copper/water heat pipe outfitted with a cold reservoir and used air as the NonCondensable Gas (NCG). The respective thermodynamic properties of water were analyzed and the study was performed at the vapor-NCG interface for various operating pressures. The results indicated that the starting point of the VCHP function is significantly based on the amount of NCG content in the heat pipe and on the superheat required for boiling.

\subsection{Thermal diodes}

A simple thermal diode can be a thermosyphon in which the gravitational force supplies the irregularity when positioned appropriately. A variety of aerospace and ground based applications make use of thermal diodes which includes space crafts. The device is alsoused in modern renewable energy systems particularly where heat transfer in one direction is a requirement. However, due to the high initial capital expenditure and complexity in retrofitting such systems, commercialization and interest has increased only steadily. Fig. 7 displays the schematic of a liquid trap diode in the reverse mode. Fang and Xia studied the thermal performance of a novel Bidirectional Partition Fluid Thermal Diode (BPFTD) for the function of providing solar heating and passive cooling respectively. The experimental analysis was carried out by testing the BPFTD with two identical hot boxes with similar wall configuration andcomparisons were established with a water-wall of optimum thickness. Test results yielded that the BPFTD had a higher heating performance compared to its water-wall counterpart with additional findings confirming an increase in heat supply of around $140 \%$ when a single glazing cover without night ventilation is utilized when compared to the water-wall respectively. Varga et al. carried out tests to evaluate the performance of thermal diodepanels incorporating heat pipes for passive cooling in buildings in Portugal. The manufactured experimental set-up included nine copper/water bent heat pipes with a diameter of 12.7 $\mathrm{mm}$ welded to aluminum sheets along with the thermal diode panels respectively. The thermal and physical properties were tested using a finite element heat transfer model combined with an optimization procedure for both forward and backward heat transfer. The work concluded the agreement of the applied model with the experimental procedure. Further, the results revealed a significant increase in the forward heat transfer results in comparison to its backward counterpart experimentally investigated the temperature stratification in a solar hot water storage tank. The experiment proposed four different storage tank designs involving thermal diodes for its operation. The results of the test examined that the socalledexpress-elevator design displayed the highest amount of stratification during both heating and cooling periods in comparison tothe other proposed designs. Consequently, the work concluded thebright future scope of optimizing the geometric parameters of thermal diodes to obtain an improved rate of stratification. Omer et al. analyzed a thermoelectric refrigeration system integrated with thermal diodes to study the performance of PCMs. The fabricated system built for test included a $150 \mathrm{~W}$ thermoelectric refrigeration system. The performance of the proposed system was compared to another similar system without integrated thermal diodes. The results revealed the feasibility of utilizing thermal diodes between the thermoelectric cells and the PCM in order to prevent heat leakage. The results also displayed an improved performance of the system incorporating thermal diodes in the storage ability of the thermoelectric refrigeration system in comparison to its counterpart.

\section{Results summary}

From the reviewed heat pipe technologies for terrestrial and aerospace applications, it is considered that each system has its own advantages and 
limitations based largely on working conditions. Table 1 summarizes the reviewed heat pipe systems displaying the typical applications and range of operating temperatures. The figure of merit is estimated based on the working fluid properties based on operating temperatures

\section{Discussion}

With reference to Table 1, the principal properties and applications were obtained based on relevant commercial equipment. As observed, the working range for tubular heat pipe systems is at intermediate temperatures with average operating temperature being $335.5 \mathrm{~K}$. The industrial manufacturers for the respective highlight the ability of the copper-water sintered-powdered wicked heat pipe device to transfer thermal energy efficiently regardless of orientation and gravitational effects with the density estimation of 50 $\mathrm{W} / \mathrm{cm} 2$.

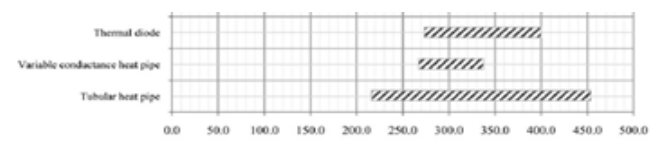

Fig.13.Merit No. of candidate heat pipe working fluids for intermediate temperatures

Other imperative features of tubular heat pipe systems include compactness, integrity into heat sinks and cold plates through mechanical interference and long-life reliability which is a highly desirable factor for a majority of terrestrial applications. A graphical representation of the operating temperature range of reviewed heat pipe systems is displayed in Fig. 12. It is seen that the range of working temperatures is maximum for SHP systems highlighting its superiority to replace SHP systems in space applications. Moreover, from extensive literature, it is asserted that the integration of the sorption cooler with LHP systems has recorded average evaporator thermal resistances of 0.07-0.08 K/W with heat fluxes of 100-200 W/cm2. Further observations from Fig. 12 include the temperature range limitations for micro heat pipe systems which has a differential of only $30 \mathrm{~K}$ since nearly all of the high-performance utility includes enhancing heat transfer of electronic components, namely computer central processing units and microprocessors which operate at working temperatures of313-343 K.Typical operating temperatures for heat pipe systems utilized interrestrial applications range from $293 \mathrm{~K}$ to $393 \mathrm{~K}$. Choice of working fluid is a major contemplation in identifying appropriate heat pipe assemblies and candidate working fluids are summarized in Table 2 for intermediate temperatures. The Merit No. is a useful Indicator in determining the maximum heat transport capability in terms of the fluid properties and is determined by Eq. (1).Fig. 13 displays the Merit No. variation with increasing intermediate operating temperatures for a range of heat pipe working fluids. With reference to the figure, a significant increase in MeritNo. of $64.2 \%$ for Water is observed while notable decreasing gradient of $95.1 \%$ and $59.0 \%$ is observed for Ammonia and Acetone with increasing temperatures respectively. As expected, water demonstrates a much superior Merit No. in comparison to other candidate fluids within the operating temperature range, thus confirming the historical dominance as the principal working fluid in most heat pipe applications.

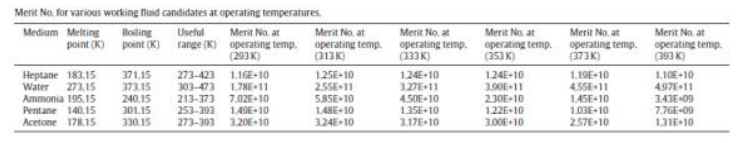

\section{Conclusion}

The technological development of research into the utilization of heat pipes for efficient and passive heat transport is rapidly increasing through the use of advanced computation and complex experimentation techniques. This study reviewed some of the general heat pipe systems used in building and ground applications including heat recovery and renewable energy methodologies in Order to determine the typical heat pipe arrangements along with their working temperature range for use in the respective. The investigation revealed that heat pipes incorporated with sorption phenomenon display greater heat transfer capacity and tubular heat pipes have the highest working range on average with the maximum operating temperature from all reviewed systems being $453 \mathrm{~K}$ for the tubular heat pipe arrangement respectively. The study's conclusions are based on the research of various industrial products utilizing the heat pipe systems for theiroperations. Imperative factors including the figure of merit were calculated and compared for various suitable heat pipe working fluids. The findings revealed that water displayed the highest average Merit Number in comparison to ammonia and acetone forthe operating temperature range of 293-393 K.

\section{References}

Cengel YA. Heat and mass transfer - a practical approach. Third edition NewYork, NY 10020, USA: McGraw-Hill 2006. p. 592-597.

Reay D, Kew P. Heat pipes - theory, design and applications fifth edition OxfordOX2 8DP, USA: ButterworthHeinemann; 2006

El-Baky MAA, Mohamed MM. Heat pipe heat exchanger for heat recovery in airconditioning. Applied Thermal Engineering 2007;27:795-801

Noie-Baghban SH, Majideian GR. Waste heat recovery using heat pipe heatexchanger (HPHE) for surgery rooms in hospitals. Applied Thermal engineering 2000;20:1271-82

Yau YH, Ahmadzadehtalatapeh M. A review on the application of horizontalheat pipe heat exchangers in air conditioning systems in the tropics Applied Thermal Engineering 2010;30:77-8 
Hussein HMS, El-Ghetany HH, Nada SA.Performance of wickless heat pipe flatplate solar collectors having different pipes cross sections geometries and fillingratios. Energonversion and Management2006;47:1539-49.

Rittidech S, Wannapakne S. Experimental study of the performance of a solarcollector by closed-end oscillating heat pipe (CEOHP). Applied Thermal engineering2007;27:1978-

Liao $Q$, Jen T-C, Chen $Q$, Li L, Cui W. Heat transfer performance in 3Dinternally finned heat pipe. International Journal of Heat and Mass Transfer 2007;50:1231

Joudi KA, Witwit AM. Improvements of gravity assisted wickless heat pipes.Energy Conversion \& Management 2000;41:2041-61

Sauciuc I, Akbarzadeh A, Johnson P. Temperature control using variable conductanceclosed two-phase heat pipe. International Communications in Heatand Mass Transfer 1996;23(3):427-33

Fang X, Xia L. Heating performance investigation of a bidirectional partitionfluid thermal diode. Renewable Energy 2010;35:679-8

Varga S, Oliveira AC, Afonso CF. Characterisation of thermal diode panels foruse in the cooling season in buildings. Energy and Buildings 2002;34:227-3

Rhee J, Campbell A, Mariadass A, Morhous B. Temperature stratification fromthermal diodes in solar hot water storage tank. Solar Energy2010;84:507-11
Omer SA, Riffat SB, Ma X. Experimental investigation of a thermoelectric refrigeration system employing a phase change material integrated with thermaldiode. Applied Thermal Engineering 2001;1:1265-7

$\mathrm{Qu}$ W, Ma HB. Theoretical analysis of startup of a pulsating heat pipe .InternationalJournal of Heat and Mass Transfer 2007;50:2309-16.

Wang S, Lin Z, Zhang W, Chen J. Experimental study on pulsating heat pipewith functional thermal fluids. International Journal of Heat and Mass Transfer 2009;52:5276-

Yang H, Khandekar S, Groll M. Operational limit of closed loop pulsating heatpipes. Applied Thermal Engineering 2008;28:49-59

Wang S, Zhang W, Zhang X, Chen J. Study on start-up characteristics of loopheat pipe under low-power. International Journal of Heat and Mass Transfer2011;54:1002

Zhao X, Wang Z, Tang Q. Theoretical investigation of the performance of a novelloop heat pipe solar water heating system for use in Beijing, China. Applied Thermal Engineering 2010;30:2526-

Kaya T, Goldak J. Numerical analysis of heat and mass transfer in the capillarystructure of a loop heat pipe. International Journal of Heat and Mass Transfer

2006;49:3211-20. 